\title{
Nonvesicular Release of Glutamate by Glial xCT Transporters Suppresses Glutamate Receptor Clustering In Vivo
}

\author{
Hrvoje Augustin, ${ }^{\star}$ Yael Grosjean, ${ }^{\star}$ Kaiyun Chen, Qi Sheng, and David E. Featherstone \\ Biological Sciences, University of Illinois at Chicago, Chicago, Illinois 60607
}

We hypothesized that cystine/glutamate transporters (xCTs) might be critical regulators of ambient extracellular glutamate levels in the nervous system and that misregulation of this glutamate pool might have important neurophysiological and/or behavioral consequences. To test this idea, we identified and functionally characterized a novel Drosophila xCT gene, which we subsequently named "genderblind" $(g b)$. Genderblind is expressed in a previously overlooked subset of peripheral and central glia. Genetic elimination of $g b$ causes a $50 \%$ reduction in extracellular glutamate concentration, demonstrating that XCT transporters are important regulators of extracellular glutamate. Consistent with previous studies showing that extracellular glutamate regulates postsynaptic glutamate receptor clustering, $g b$ mutants show a large (200-300\%) increase in the number of postsynaptic glutamate receptors. This increase in postsynaptic receptor abundance is not accompanied by other obvious synaptic changes and is completely rescued when synapses are cultured in wild-type levels of glutamate. Additional in situ pharmacology suggests that glutamate-mediated suppression of glutamate receptor clustering depends on receptor desensitization. Together, our results suggest that (1) xCT transporters are critical for regulation of ambient extracellular glutamate in vivo; (2) ambient extracellular glutamate maintains some receptors constitutively desensitized in vivo; and (3) constitutive desensitization of ionotropic glutamate receptors suppresses their ability to cluster at synapses.

Key words: glia; glutamate; glutamate receptor; neurotransmission; synapse; synaptic plasticity

\section{Introduction}

Ionotropic glutamate receptors (iGluRs) mediate most neurotransmission in mammalian brains, and changes in the localization and/or number of iGluRs are thought to underlie learning, memory, and many different neuropathologies. Here, we show that the cystine/glutamate exchange $\left(\mathrm{x}_{\mathrm{c}}^{-}\right)$system is a very strong novel regulator of synaptic iGluR abundance in vivo.

The $\mathrm{x}_{\mathrm{c}}^{-}$system mediates sodium-independent 1:1 exchange between extracellular cystine and intracellular glutamate (Sato et al., 1999, 2000, 2002; Kanai and Endou, 2001; Kim et al., 2001; Hosoya et al., 2002) and is generally assumed to function as a glutamate-dependent cystine-uptake mechanism for glutathione synthesis during oxidative stress (Bannai and Ishii, 1982; Bannai et al., 1984; Christensen, 1990; Shih et al., 2006). However, increasing evidence suggests that the $\mathrm{x}_{\mathrm{c}}^{-}$system, at least in the ner-

Received Aug. 23, 2006; revised Nov. 26, 2006; accepted Nov. 26, 2006.

This work was funded by a grant from the Muscular Dystrophy Association and National Institutes of HealthNational Institute of Neurological Disorders and Stroke Grant R01NS045628 (D.F.). We thank Pei-San Ng for technical assistance and H. BassiriRad and H. L. Sehtiya (University of Illinois at Chicago, Chicago, IL) for advice and assistance measuring amino acids by HPLC. We also thank M. Freeman (University of Massachusetts Medical School, Worcester, MA) and, especially, V. Auld and D. Brink (University of British Columbia Vancouver, Vancouver, British Columbia, Canada) for very helpful discussions and ideas regarding the NMJ glia. We are also grateful to the Bloomington Drosophila Stock Center (Bloomington, IN), Berkeley Drosophila Genome Project Gene Disruption Project (Berkeley, (A), and the University of lowa Developmental Studies Hybridoma Bank (lowa (ity, IA), for providing essentia reagents and services for this project.

*H.A. and Y.J. contributed equally to this work.

Correspondence should be addressed to David Featherstone, Department of Biological Sciences, University of Illinois at Chicago, 840 West Taylor Street (M/C 067), Chicago, IL 60607. E-mail: def@uic.edu.

DOI:10.1523/JNEUROSCI.4770-06.2007

Copyright $\odot 2007$ Society for Neuroscience $\quad 0270-6474 / 07 / 270111-13 \$ 15.00 / 0$ vous system, may also be a critical regulator of extracellular glutamate.

Minor alterations in ambient extracellular glutamate by the $\mathrm{x}_{\mathrm{c}}^{-}$system have the potential to dramatically alter glutamatergic neurotransmission. For example, human CSF glutamate levels typically range from 3 to $7 \mu \mathrm{M}$ in healthy subjects (Tucci et al., 1998; Rainesalo et al., 2004). This concentration is sufficient for activation and desensitization of a large fraction of endogenous glutamate receptors, particularly NMDA receptors $\left(\mathrm{EC}_{50}=6-8\right.$ $\mu \mathrm{M})$, which are known to be critical for phenomena such as learning and memory (Jahn et al., 1998; Lerma et al., 2001; NahumLevy et al., 2001). Circumstantial evidence from mammals, nematodes, and flies also implicates physiological levels of extracellular glutamate in regulation of glutamate receptor clustering (Lissin et al., 1999; Featherstone et al., 2002; Grunwald et al., 2004).

The proteins mediating $\mathrm{x}_{\mathrm{c}}^{-}$system transport were recently identified by expression cloning in Xenopus oocytes (Sato et al., 1999). $x_{c}^{-}$system transporters are highly conserved heterodimeric transmembrane proteins composed of one "heavy" $4 \mathrm{~F} 2 \mathrm{hc}$ subunit and one "light" cystine/glutamate transporter ( $\mathrm{xCT})$ subunit. 4F2hc is an accessory subunit that regulates protein trafficking and is used by several different types of amino acid transporter. $\mathrm{xCT}$ is required for $\mathrm{x}_{\mathrm{c}}^{-}$system amino acid selectivity and transport and is found only in $\mathrm{x}_{\mathrm{c}}^{-}$system transporters (Sato et al., 1999; Chillaron et al., 2001; Wagner et al., 2001; Verrey et al., 2004). Increasingly, $x_{c}^{-}$system transporters are referred to as "xCT transporters," in acknowledgment of their molecular composition. Thus, genetic elimination of $\mathrm{xCT}$ proteins allows us to 
determine whether the $\mathrm{x}_{\mathrm{c}}^{-}$system regulates glutamatergic synapse development and/or function.

Using Drosophila, we identified, named, and functionally studied a highly conserved but previously undescribed $\mathrm{xCT}$ protein, which we named "Genderblind" (GB; also known as CG6070), based on a mutant homosexual behavior phenotype (Grosjean et al., unpublished results). Our results suggest that GB-based xCT transporters secrete glutamate from a previously undescribed subset of central and peripheral glia, and this glutamate acts as a strong regulator of glutamate receptor clustering via a desensitization-dependent mechanism. These findings represent the identification of a novel role for the $\mathrm{x}_{\mathrm{c}}^{-}$system and $\mathrm{a}$ fundamentally new mechanism for spatially distributed modulation of glutamatergic signaling.

\section{Materials and Methods}

Molecular biology and biochemistry. For reverse transcription (RT)-PCR, total RNA was isolated using Trizol (Invitrogen, Carlsbad, CA) extraction (Roberts, 1998). RNA (500 ng; measured spectrophotometrically) was reverse transcribed, and $10 \%$ of the cDNA product was used to amplify $g b$ and actin cDNA fragments by PCR. A 130 bp fragment of $g b$ was amplified using the following primers: CCATGAGGGGTATGATCAGTG and ATTTATGTGCTGGCCAATGTG. A $200 \mathrm{bp}$ fragment of actin was simultaneously amplified as a control using the following primers: CAAGCCTCCATTCCCAAGAAC and CGTGAAATCGTCCGTGACATC. For each lane shown in Figure 1 and RT-PCR in supplemental material (available at www.jneurosci.org), total RNA was isolated from a specific developmental stage, gender, or tagma (head, thorax, or abdomen). The amount of RNA was then quantified spectrophotometrically to control for possible differences in RNA isolation efficiency or degradation and then reverse transcribed. The resulting cDNA was then PCR amplified using $g b$ and actin-specific primers and separated by gel electrophoresis to give a semiquantitative measurement of $g b$ mRNA abundance throughout development and in specific tissues.

To make the $g b . R N A i$ transgene, two $767 \mathrm{bp}$ fragments of wild-type (WT) CG6070 were PCR amplified and cloned into the Drosophila transformation and loopless hairpin RNA interference (RNAi) expression vector pWIZ (Lee and Carthew, 2003) using Escherichia coli SURE cells (Stratagene, La Jolla, CA). The following PCR primers, which also introduce $\mathrm{XbaI}$ and BglII restriction sites (underlined) for cloning, were used: ATTCTAGACCGTCCAGCGAAATGGTC and either ATTCTAGACATCCGGCATAGGAAAAGATAC or TAAGATCTCATCCGGCATAGGAAAAGATAC. Fly transformation was subsequently performed by DNA microinjection of embryos using standard methods (Genetic Services, Cambridge, MA).

Immunocytochemistry and confocal microscopy. Unless otherwise stated, immunocytochemistry and confocal microscopy were performed as described previously (Featherstone et al., 2002, 2005; Chen et al., 2005; Liebl et al., 2005). All neuromuscular junction (NMJ) micrographs and analysis were from NMJs on larval ventral longitudinal muscles 6 and 7 (A3-A4). For NMJ glia images, dissections were performed under standard Drosophila saline with physiological levels of glutamate [(in mM) $135 \mathrm{NaCl}, 5 \mathrm{KCl}, 4 \mathrm{MgCl}_{2}, 1.8 \mathrm{CaCl}_{2}, 5 \mathrm{~N}$-Tris(hydroxymethyl)methyl2-aminoethanesulfonic acid (TES), 72 sucrose, and 2 L-glutamate]; the use of zero-calcium, zero-glutamate saline causes NMJ glia retraction. Rabbit polyclonal anti-GB antibodies were generated against a synthesized peptide SSGNPPSSIAQPAANPAEKAQ by the University of Illinois at Chicago Research Resource Center (Chicago, IL) proteomics and antibody facilities using standard methods. This peptide represents amino acids $20-40$ of the GB protein. These anti-GB antibodies were used at 1:600. Mouse monoclonal anti-CD8 antibodies (Invitrogen) were used at 1:100. Mouse monoclonal anti-GluRIIA (8B4D2) and anti-slit (C555.6) antibodies were obtained from the University of Iowa Developmental Studies Hybridoma Bank (Iowa City, IA) and used at 1:100 and 1:500, respectively. FITC-, tetramethylrhodamine isothiocyanate (TRITC)-, and cyanine 5 (Cy5)-conjugated goat anti-mouse or antirabbit secondary antibodies were obtained from Jackson ImmunoRe- search (West Grove, PA) and used at 1:400. TRITC- or Cy5-conjugated anti-horseradish peroxidase (HRP) antibodies were also obtained from Jackson ImmunoResearch and used at 1:100. For GB localization experiments, larvae were dissected in standard Drosophila saline (in mм: 135 $\mathrm{NaCl}, 5 \mathrm{KCl}, 4 \mathrm{MgCl}_{2}, 1.8 \mathrm{CaCl}_{2}, 5 \mathrm{TES}$, and 72 sucrose) supplemented with $2 \mathrm{~mm}$ glutamate and then fixed for 30-40 $\mathrm{min}$ in Bouin's fixative.

Quantitative image analysis was performed with ImageJ (National Institutes of Health, Bethesda, MD). Three-dimensional (3D) isosurface reconstructions were performed using Amira 3.1 (Mercury Computer Systems, San Diego, CA).

Immunocytochemical measurements of postsynaptic glutamate receptor abundance were made by quantifying mean postsynaptic immunofluorescence intensity relative to fluorescence in surrounding muscle tissue ( $\left.F_{\text {synapse }} / F_{\text {background membrane }}\right)$.

HPLC. For measurements of hemolymph glutamate concentration, larval hemolymph was extracted by piercing the cuticles of five thirdinstar (L3) larvae and allowing them to bleed for 5 min into $100 \mu \mathrm{l}$ of Drosophila saline. The concentration of free dissolved glutamate, glycine, and phenylalanine in each sample was measured independently by Scientific Research Consortium (St. Paul, MN) using a Beckman Coulter (Fullerton, CA) dedicated HPLC amino acid analyzer, which uses ionexchange chromatography followed by postcolumn ninhydrin reaction detection. To control for variability in hemolymph extraction efficiency and/or hemolymph evaporation between experiments, glutamate concentration in each sample was normalized to the measured concentration of phenylalanine from the same sample. Phenylalanine (e.g., the "loading control") is relatively metabolically uncoupled from glutamate and was found to be stable across samples in preliminary HPLC experiments conducted in collaboration with Drs. H. L. Sehtiya and H. BassiriRad (University of Illinois at Chicago). Dividing by glycine gave essentially identical results. Without normalization/correction, the mean value for control hemolymph glutamate concentration was $1.72 \mathrm{~mm}$, which agrees well with previous measurements. Mean hemolymph glutamate for $g b$ mutants was $1.08 \mathrm{~mm}$. Ten individually obtained and analyzed samples (representing hemolymph from a total of 50 larvae) were used for each genotype.

Receptor clustering inhibition by glutamate assays. Culture of living semi-intact larvae was performed exactly as described by Ball et al. (2003), except that the culture medium [essentially HL3 (hemolymphlike solution) plus calf serum] was supplemented with various amounts of L-glutamate, as described in Results. At the end of the specified culture time, larvae were fixed in Bouin's fixative and treated as described above for immunocytochemistry and microscopy.

Electrophysiology. All electrophysiological recordings were obtained from larval ventral longitudinal muscle 6 (A3-A4) using two-electrode voltage clamp $(-60 \mathrm{mV})$ as described previously (Featherstone et al., 2000, 2005; Liebl et al., 2005). Note that this is the same NMJ that was analyzed for all other types of experiments in this study. All dissections and electrophysiology were performed under standard Drosophila saline; the use of zero-calcium saline at any point causes NMJ glia retraction. NMJ glia are also maximally extended only when preparations are maintained in physiological (2 mM) levels of glutamate. Recordings were performed in $0 \mathrm{~mm}$ glutamate to ensure that we assayed all receptors potentially available in the membrane. To quantify the degree to which Con A, cyclothiazide, and 4-[2-(phenylsulfonylamino)ethylthio]-2,6-difluorophenoxyacetamide (PEPA) inhibited desensitization, we measured excitatory junction current (EJC) decay-phase time constants, which are proportional to rates of receptor desensitization (Mathers and Usherwood, 1976a,b, 1978).

For each $n$ (one animal), we recorded EJCs for several minutes (at 0.1-0.5 Hz), applied the drug to the bath, and recorded several more minutes of EJCs. EJC decay time constants were measured for each of the "after-treatment" EJCs and then averaged. This average was divided by the similarly measured average of "before-treatment" EJCs from the same animal to compute the "percentage of pretreatment excitatory junction current (EJC) time constant" for that animal. The data points and error bars in Figure 9D represent the mean \pm SEM percentage of pretreatment EJC time constant for several animals.

Genetics and statistics. As described in Results, $g b[$ KG07905] is a 
P-element insertion in CG6070/genderblind: P\{SUPor-P $\}$ CG6070 [KG07905]. The mutation was generated by the Berkeley Drosophila Genome Project (BDGP) Gene Disruption Project (Berkeley, CA) (Bellen et al., 2004) and is available from the Bloomington Stock Center (Bloomington, IN). Wild-type flies were Oregon $R$. The deficiency $(D f)$ used was $D f(3 R)$ Exel6206 (Parks et al., 2004), which completely deletes $g b$, as well as six more genes $5^{\prime}$ to $g b$ and eight genes $3^{\prime}$ to $g b$. Glutamate oxaloacetate transaminase (GOT) mutants (Featherstone et al., 2002) were got2[nj]/ SM1,got2[1], in which enzymatic function of GOT2, the sole cytoplasmic GOT paralog in Drosophila, is eliminated (Chase and Kankel, 1987; Caggese et al., 1994).

For comparison between two groups of normally distributed data, a Student's $t$ test was used. All tests were unpaired except for EJC decay time constant experiments, as described above. When data distributions had unequal variance or were highly skewed, $p$ values for two-group comparisons were computed using a Mann-Whitney test or Kolmogorov-Smirnov test. In figures, statistical significance is indicated by asterisks: ${ }^{\star} p<0.05 ;{ }^{\star *} p<0.01 ;{ }^{\star * *} p<0.001$.

\section{Results}

\section{Genderblind is a Drosophila $\mathrm{xCT}$ homolog}

As a first step toward determining the role of xCT transporters in flies, we used functionally identified mouse and human XCT protein sequences (Q9WTR6 and BAA82628, respectively) to bioinformatically identify all xCT homologs encoded by the Drosophila melanogaster genome. This revealed five Drosophila xCT genes: CG6070, JhI-21 (CG12317), mnd (minidiscs; CG3297), CG1607, and CG9413. The predicted protein sequence of all five Drosophila genes is highly similar to that of mammalian $\mathrm{xCT}$ subunits: full-length amino acid identity ranges from 36 to $45 \%$. Importantly, all five Drosophila genes also encode a cystine (C158 in mouse and human sequences) required for formation of disulfide bonds between mammalian xCT and 4F2hc subunits (Chillaron et al., 2001; Wagner et al., 2001; Verrey et al., 2004). Of these five genes, we prioritized CG6070 for additional investigation based on relatively high sequence similarity to mammalian $\mathrm{xCT}$ proteins (43\% amino acid identity between CG6070 and human $\mathrm{xCT}$ ) and RNA in situ hybridization results from the BDGP Gene Expression Database that show strong CG6070 expression throughout the developing nervous system (Tomancak et al., 2002). The amino acid sequence of Drosophila CG6070 aligned with $\mathrm{xCT}$ protein sequences from other species is shown in supplemental Figure 1 (available at www.jneurosci.org as supplemental material). Based on a striking increase in homosexual courtship displayed by $g b$ mutant flies (Grosjean et al., unpublished results), we named the predicted gene CG6070"genderblind."

\section{Genderblind is expressed throughout development}

Neither the $g b$ gene nor its protein product (GB) has been described previously. As a first step in characterization of $g b$, we determined when the gene is expressed using RT-PCR. To do this, we used RT-PCR to assay for the presence of $g b$ transcript throughout development and in specific regions of the adult fly. As shown in Figure 1 and supplemental material (available at www.jneurosci.org), $g b$ transcript was readily amplified from all Drosophila life stages, including unfertilized embryos, but not from deficiency mutants in which the $g b$ gene is completely deleted. Based on these experiments, we conclude that $g b$ transcript is maternally loaded into embryos and then robustly expressed throughout development.

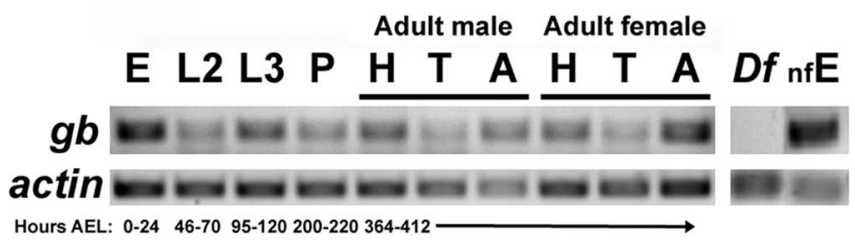

Figure 1. GB is expressed throughout development. Representative RT-PCR measurements of relative genderblind and actin 5C transcript levels throughout development and in specific regions of adult male and female bodies. An equal quantity of RNA (measured spectrophotometrically) was isolated from each designated tissue type and used to produce the RT-PCR product shown in each lane. E, Embryos, $L 2$, second-instar larvae; $P$, pupae; $H$, adult head; $T$, adult thorax; $A$, adult abdomen; Df, first-instar larval Df(3R)Exel6206 mutants (negative control); nfE, unfertilized embryos (showing heavy maternal $g b$ RNA contribution). The age in hours after egg laying (AEL) at $25^{\circ} \mathrm{C}$ is shown below the lane images.

\section{Genderblind is expressed in a functionally undescribed subset of peripheral and central glia}

According to RNA in situ hybridization data from the Berkeley Drosophila Gene Expression Pattern Database, which contains embryonic expression data for approximately one-third of the Drosophila genome, $g b$ mRNA is highly expressed in embryonic brain, including, specifically, "surface glia" (Tomancak et al., 2002). This is consistent with recent studies examining mammalian $\mathrm{xCT}$ distribution using antibodies for the first time (Burdo et al., 2006; Shih et al., 2006), which determined that mammalian $\mathrm{xCT}$ was most abundant in "border areas between the brain proper and periphery" (Burdo et al., 2006), consonant with an earlier in situ study concluding that mouse xCT RNA is "especially abundant in several regions facing the CSF," including ventricle walls and meninges (Sato et al., 2002).

To determine where GB protein is localized, we generated polyclonal antibodies against a GB-specific intracellular N-terminal sequence (amino acids 30-60; QPAANPAEKAQCREGSAESDS). Immunoreactivity of this antibody was eliminated after deletion of the $g b$ gene and significantly reduced after expression of $g b$ RNAi (supplemental material, available at www.jneurosci.org), demonstrating that this antibody is specific for GB protein.

Cellular neuroanatomy in Drosophila is particularly well described in the larval periphery, especially in reference to glutamatergic NMJs. Using our GB antibody and laser-scanning confocal fluorescence microscopy, we noticed that GB immunoreactivity was strong in the vicinity of neuromuscular junctions. As shown in Figure $2 A-D$, GB immunoreactivity appears to form a "blob" of immunoreactivity in the proximal region of NMJs viewed as confocal stacks with the $z$-axis perpendicular to postsynaptic muscles. To determine what this blob might be, we used the Drosophila Gal4 UAS system (Brand and Perrimon, 1993) to mark the entire cell membrane of specific tissues with a transmembrane CD8::green fluorescent protein (GFP) transgene and then examined the distribution of this marker relative to GB by simultaneously staining with anti-GB and anti-CD8 antibodies. GB immunoreactivity did not overlap with either neuronal [embryonic lethal abnormal visual system (elav)-Gal4] or muscle (24B-Gal4) membrane (Fig. 2A,B,E). To detect NMJ-associated glia, we expressed CD8::GFP under control of a repo-Gal4 driver and then visualized repo-positive cells using anti-CD8 antibodies (Fig. 2C). Repo encodes a glia-specific homeodomain protein and is expressed in a large subset of Drosophila glia (Xiong et al., 1994). Repo-gal4;UAS-CD8::GFP verified that larval NMJs are indeed intimately associated with repo-positive glial cells, but GB immunoreactivity only partially overlapped that of repo-gal4;UAS-CD8::GFP 
(Fig. 2C,E), suggesting that NMJ expression of GB is not associated with repo-positive glia. We next tried expressing CD8::GFP under control of MZ840-Gal4, which drives expression in another subset of glia, including midline glia previously reported as expressing CG6070 transcript (Kearney et al., 2004). MZ840-marked cell membranes were also visible at the NMJ but did not overlap with any other marker, including GB (Fig. $2 D, E)$. Additional investigation of $M Z 840$ Gal4 revealed it to be a weak driver in larval muscle cells. Larval body wall muscles surround boutons with dense folds of membrane called "subsynaptic reticulum" (SSR). Because of the abundance of SSR membrane, immunoreactivity for larval muscle membrane proteins appears most prominent near the NMJ, even if the proteins are evenly distributed within the muscle plasma membrane (Fig. 2B,D). Quantification of overlap between different NMJ tissue markers is shown in Figure 2E. This quantification supports the conclusion that although GB is expressed at the NMJ, it is not expressed in any previously molecularly defined NMJ cell subtype (neuron, muscle, or repo-positive glia).

To better understand the relationship between GB and the larval NMJ, we generated $3 \mathrm{D}$ isosurface reconstructions from multichannel optical sections gathered using confocal fluorescent microscopy. Results from some of these experiments are shown in Figure $2 \mathrm{~F}-\mathrm{H}$. In Figure $2 \mathrm{~F}$, GBexpressing cells are visualized with anti-GB antibodies, motor neuron terminals are visualized with anti-HRP antibodies (which recognize all neuronal membrane), and the repo-positive NMJ glial cell is marked by repo-Gal4-driven CD8::GFP and visualized with anti-CD8 antibodies. The view in Figure $2 F$ is looking along the $z$-axis of the confocal sections, perpendicular to the muscle membranes, as depicted in the $Z$-projections shown in Figure $2 A-D$. As in Figure $2 A-D$, the repo- and GB-positive cells in Figure $2 F$ seem to form blobs near the proximal part of the NMJ (where the axons first encounter muscle tissue). However, when the $z$-axis of an NMJ reconstruction is rotated such that the NMJ is viewed from the "side," the relationship between the repo-positive cell, the GB-positive cell, and the presynaptic terminals becomes clear. Figure $2 G$ shows the data from Figure $2 F$, rotated and enlarged. As shown in the figure, the repo-positive cell is tightly associated with the peripheral nerve and proximal part of the terminal near the point at which the motor axons first encounter the postsynaptic muscle (data not shown) and begin branching. GB-positive cells are also associated with peripheral motor axons and the proximal part of motor terminals. However, the GB-positive cell ensheaths the repo-positive cell and thus appears to form the "outermost" layer of the peripheral axon wrapping and proximal motor terminal covering. DAPI ( $4^{\prime}, 6^{\prime}$-diamidino-2-phenylindole dihydrochloride) staining (data not shown) and examination of many images suggest that the nuclei of both GB- and repo-positive cells are
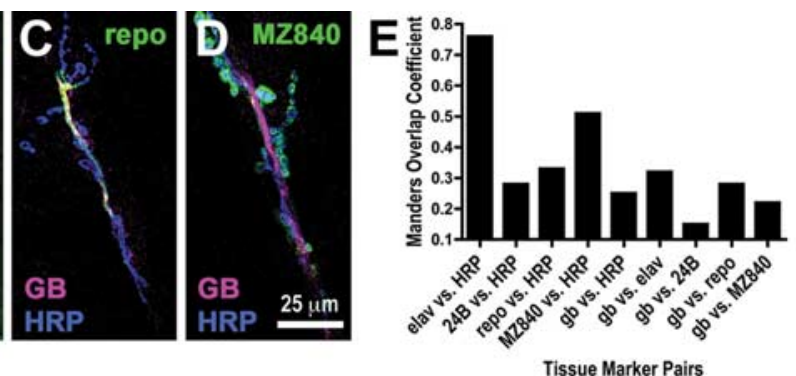

Tissue Marker Pairs

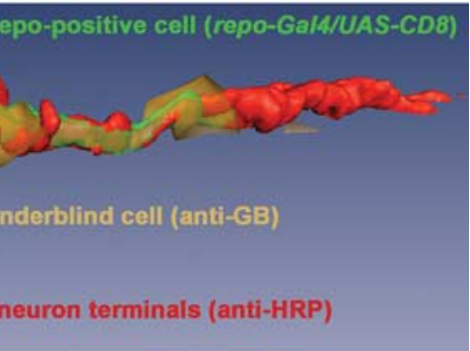
SSR subset

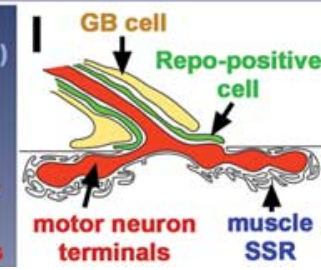

(MZ840-GaIAUAS-CD8)
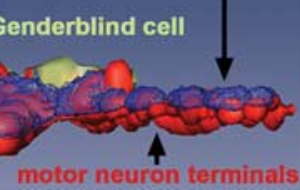

terminals

Figure 2. $G B$ is expressed in a specific subset of NMJ-associated glia. $A-D$, Confocal projections of third-instar larval NMJs on ventral longitudinal muscles 6 and 7, stained with antibodies against GB (magenta), HRP (which allows visualization of all I, Cross-sectional diagram of a larval NMJ, showing the arrangement of presynaptic motor neuron terminals, postsynaptic muscle membrane, and NMJ-associated glia.

associated with peripheral nerves and that these glia extend processes only over the proximal regions of the NMJ. The distal tips of motor neuron terminals never appear to be covered in any glia but are buried in postsynaptic muscle, as shown by the presence of MZ840-marked SSR membrane over distal boutons (Fig. $2 \mathrm{H}$ ). Our examination of larval NMJs suggests that Drosophila larval motor terminals are almost completely buried in either glia or muscle, and NMJs are collaborations between at least four types of cell: presynaptic motor neurons, postsynaptic muscles, repopositive glia, and GB-positive glia. A summary of this conclusion is diagrammed in Figure $2 I$.

GB is also expressed in the larval CNS (Fig. 3). The larval CNS is comprised of three prominent structures (Fig. 3A): two optic lobes and a ventral nerve cord (VNC). In the VNC, most GB immunoreactivity is in cells near the dorsal cortical regions (Fig. $3 B$ ); relatively little GB immunoreactivity is detectable in the more ventral regions of the VNC (Fig. $3 C$ ), except where both GB and repo are expressed in peripheral glia ensheathing the segmental nerves leading to the NMJs (Fig. $3 B, C, E$, arrows) as described above (Fig. 2). As in the NMJ, GB in the VNC is not expressed in neurons (Fig. 3B). However, GB immunoreactivity in the VNC does appear to share some overlap with repo-positive 

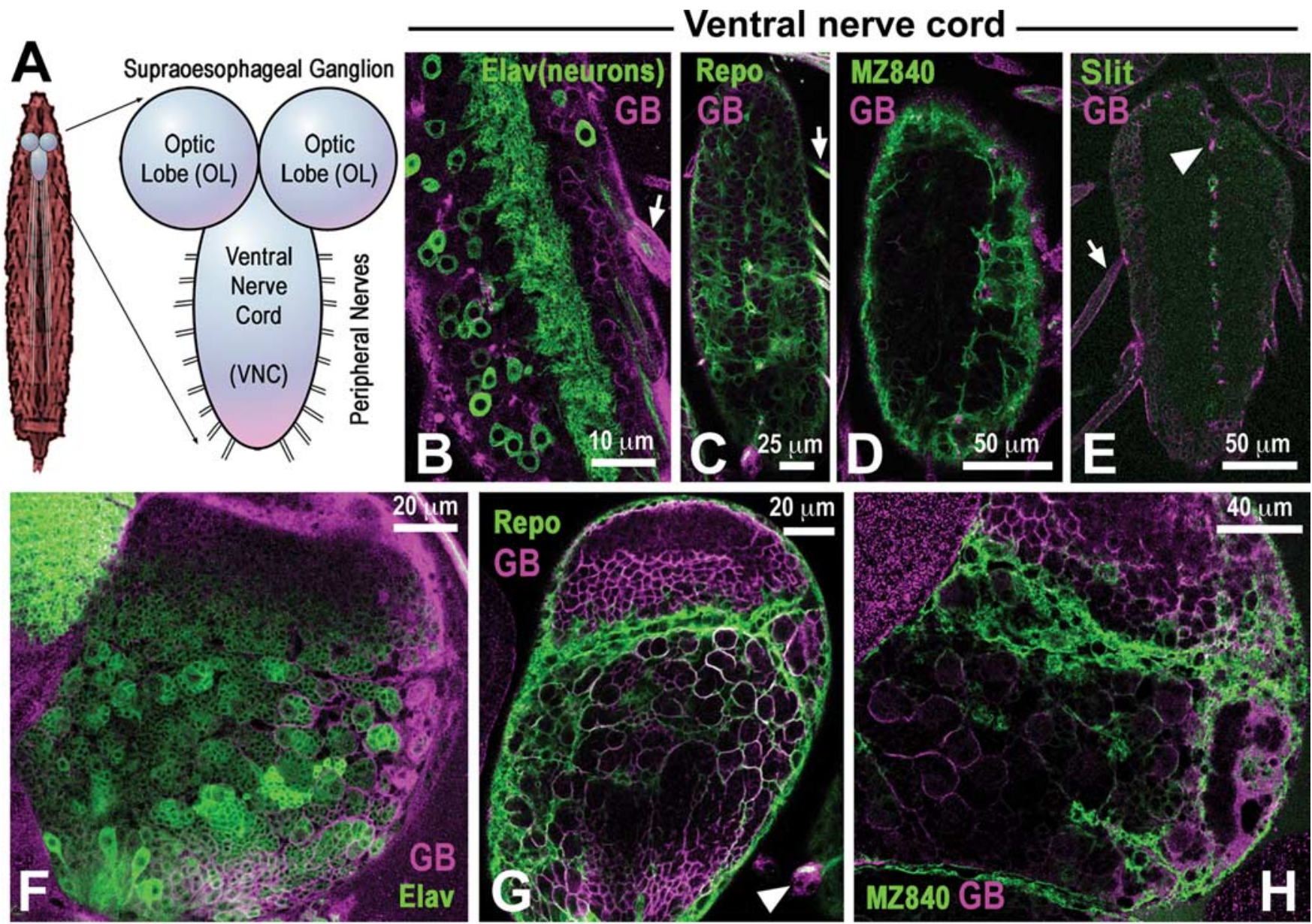

\section{Optic lobe}

Figure 3. GB is expressed in a specific subset of CNS glia. $A$, Diagram of neuromuscular anatomy in a third-instar larva. $\boldsymbol{B}-\boldsymbol{H}$, Confocal projections of larval ventral ganglia, stained with antibodies against GB (magenta) and CD8 (green). B, CD8 expression was driven with the pan-neuronal driver elav-Gal4 (Elav). C, CD8 was driven with the glial subset driver repo-Gal4 (Repo). D, CD8 was driven with MZ840 -Gal4 (MZ840). $\boldsymbol{E}$, The VNC is stained with antibodies against GB (magenta) and the midline glia marker slit (green). Arrows in $\boldsymbol{B}, \boldsymbol{C}$, and $\boldsymbol{E}$ indicate peripheral glial ensheating segmental nerves. Arrowhead in $\boldsymbol{E}$ indicates a midline glial cell expressing GB. $\boldsymbol{F}$ - $\boldsymbol{H}$, Confocal projections of larval optic lobes, stained with antibodies against GB (magenta) and CD8 (green). CD8 was driven under control of elav-Gal4 $(\boldsymbol{F})$, repo-Gal4 $(\boldsymbol{G})$, or $M Z 840-G a / 4(\boldsymbol{H})$, as labeled and described above. Arrowhead in $\mathbf{G}$ indicates $\mathrm{GB}$ expression in an unidentified structure near the optic lobes.

glia (Fig. 3C). Because of the density of CNS tissue, we were unable to gain insight into this overlap using $3 \mathrm{D}$ isosurface reconstructions, but the presence of some overlap in single confocal sections (Fig. 3C) supports the idea that GB is expressed in a subset of repo-positive CNS glia. In the more ventral regions of the $\mathrm{VNC}$, we found that $\mathrm{GB}$ is prominently expressed in a subset of VNC midline glia (Fig. 3C-E). GB expression in the VNC midline does not overlap expression of MZ840, which appears to drive strong expression in larval VNC perineurial glia (Fig. 3D). $\mathrm{GB}$ is also not expressed in midline glia expressing slit (Fig. $3 E$ ). CG6070 was previously reported to be expressed in "medial-most cell body glia" (MM-CBG) based on embryonic in situ studies (Kearney et al., 2004). We cannot definitively confirm that GB immunoreactivity in the larval VNC midline is caused by MMCBG expression, because previous methods for MM-CBG identification relied on MZ840-Gal4 expression in embryos (Kearney et al., 2004), and larval MZ840-Gal4 expression clearly does not identify a subset of midline glia in larvae (Fig. $3 D$ ). The function of MM-CBG glia is unknown.

In the optic lobes, GB immunoreactivity surrounds small clusters (four to six cells in diameter) of neurons (Fig. $3 \mathrm{~F}-\mathrm{H}$ ). Repo-Gal4 also drives expression surrounding small clusters of cells (Fig. 3G). Thus, some repo-positive glia in the optic lobes express GB, although distribution of GB and repo-positive cell types in other areas of the optic lobe is distinctly nonoverlapping (Fig. 3G). As in other tissues, GB is not expressed in neurons (Fig. $3 F$ ) or in MZ840-marked cells (Fig. 3H).

Overall, GB protein distribution in Drosophila is consistent with the pattern of expression of $\mathrm{xCT}$ recently observed in mammals, in that GB is highly expressed at interfaces between the nervous system and extracellular milieu. GB is not expressed in neurons, based on a clear lack of overlap between anti-GB immunoreactivity and neuronal membrane. By default, we must therefore conclude that GB is expressed in glia, because, by definition, glia are non-neuronal cells that intermingle with the peripheral nervous system and CNS. To our knowledge, no markers for all Drosophila glia have yet been identified. The partial overlap between repo-Gal4;UAS-CD8::GFP and anti-GB immunoreactivity in the CNS and the close association between repo-Gal4 and GB in the NMJ suggest that GB is expressed in a previously undefined subset of glia. Glia associated with Drosophila larval NMJs have recently been reported (Brink et al., 2005; Chen et al., 2005) but are only beginning to be described in any detail (Brink et al., 2005; Banerjee et al., 2006) (D. Brink and V. Auld, personal communi- 
cation). Our data are consistent with the conclusion that the repo-positive cell at the NMJ is "inner glia" (termed "Schwann cell" in mammals), and the GB-positive cell is "perineurial glia" (termed "perineurium” in mammals). Drosophila perineurial glia are particularly interesting because they are morphologically regulated by neuropeptide transmission (Yager et al., 2001), but their function in the nervous system is unclear. In the CNS, however, GB does not appear to be expressed in perineurial glia, suggesting that current functional and anatomical definitions of Drosophila glia do not necessarily predict molecular components or function.

\section{Genderblind maintains high} extracellular glutamate levels

Sequence analysis predicts that GB forms an essential xCT transporter subunit for cystine-dependent glutamate secretion. If this is true, then extracellular glutamate concentration should be reduced in the absence of GB function. To test this prediction, we measured glutamate in larval hemolymph. We examined larval hemolymph because larval hemolymph is relatively easy to extract compared with other Drosophila body fluids and because our immunocytochemical experiments (Figs. 2,3 ) confirmed that GB-expressing glia are in contact with larval hemolymph. Previous studies measured Drosophila larval hemolymph glutamate concentration using a variety of techniques (Echalier, 1997). Reported values of larval hemolymph glutamate range from 0.8 to $10 \mathrm{~mm}$ (McDonald, 1975; Echalier, 1997; Pierce et al., 1999). Meta-analysis of multiple studies yields an average value of $2.4 \mathrm{~mm}$ for larval hemo-

lymph glutamate. Consistent with these previous reports, our HPLC measurements of free hemolymph glutamate from control ("precise excision”) larvae averaged $1.72 \mathrm{~mm}$.

We chose to disrupt GB function genetically because specific pharmacological modulators of $\mathrm{x}_{\mathrm{c}}^{-}$system function have not yet been developed. Previous studies of $\mathrm{x}_{\mathrm{c}}^{-}$system function relied on the use of nontransportable amino acid analogs, such as homocysteic acid or (S)-4-carboxyphenylglycine (CPG). Unfortunately, these are nonspecific inhibitors. Homocysteic acid has long been known as an endogenous NMDA receptor agonist (Olney et al., 1987), and CPG is marketed primarily as a metabotropic glutamate receptor antagonist.

The BDGP Gene Disruption Project (Bellen et al., 2004) is working to generate transposable element insertion mutations in every gene in the Drosophila genome. Among the mutations generated to date is $P\{S U P o r-P\} C G 6070[K G 07905]$. P\{SUPor$P\} C G 6070[$ KG07905] mutants carry a $P\{S U P o r-P\}$ transposable element in the first exon of the $g b$ gene (Fig. $4 A$ ). For brevity and clarity, we hereafter refer to $P\{S U P o r-P\} C G 6070[$ KG07905] mutants as " $g b[K G 07905]$." The $P\{S U P o r-P\}$ transposable element is $\mathrm{a} \sim 12 \mathrm{~kb}$ P-element engineered to maximally disrupt gene function by suppressing promoter activity (Roseman et al., 1995).
B
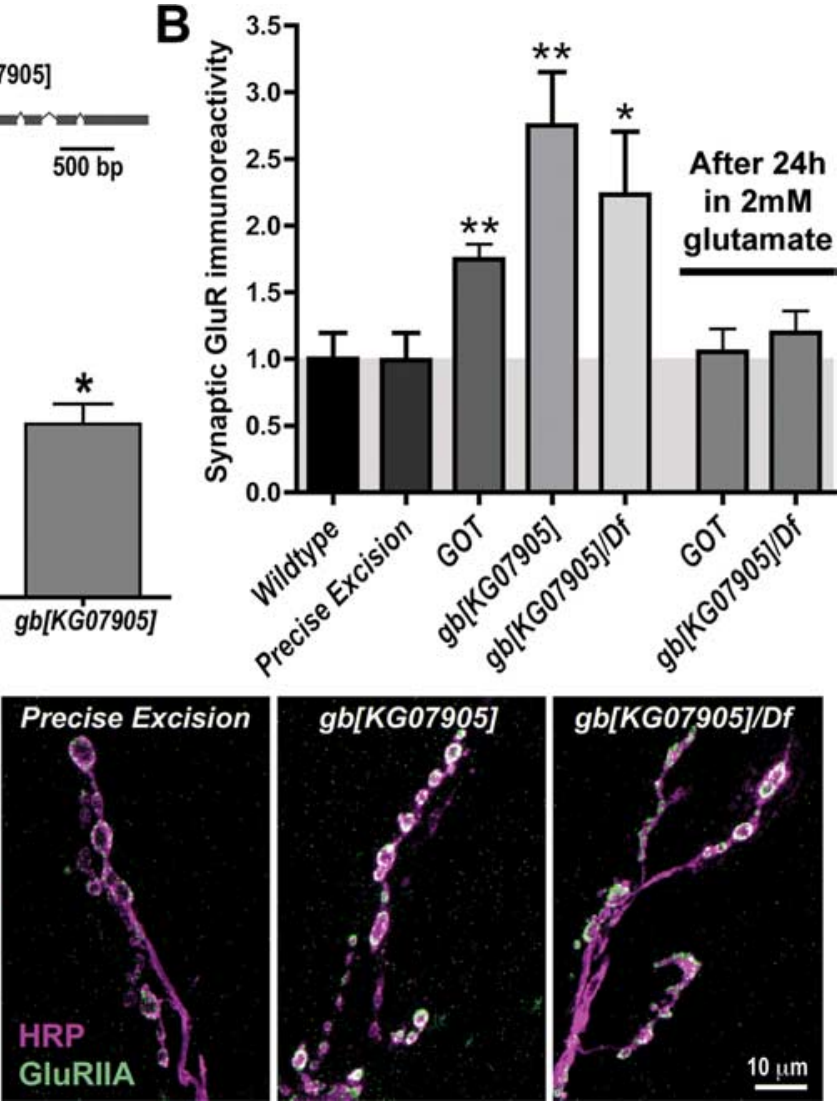

Figure 4. genderblind mutants show an increase in postsynaptic glutamate receptor immunoreactivity. $\boldsymbol{A}$, Relative concentra-

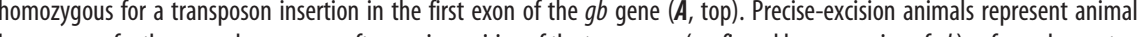
equals 10 independently analyzed samples derived from 50 larvae. To control for variability in hemolymph extraction and/or we normalized glutamate concentration measured in each sample by dividing it by the concentration of free phenylalanine in the same sample (see Materials and Methods). $\boldsymbol{B}, g b$ mutants show large increases in relative synaptic GluRIIA immunofluorescence, compared with for $24 \mathrm{~h}$ in a physiologically normal $(2 \mathrm{~mm}$ ) hemolymph glutamate concentration. C, Portions of representative confocal micrographs showing larval NMJs on ventral longitudinal muscles 6/7, stained with anti-GluRIIA antibodies (green) and the neuronal membrane marker anti-HRP (magenta). White indicates overlap. Error bars represent SEM.

Consistent with this, $g b[$ KG07905] mutants behave as null alleles (see phenotypic and genetic data below). Many transposon insertion alleles contain background mutations (Liebl and Featherstone, 2005; Liebl et al., 2006). To ensure that the phenotypes we describe were attributable to disruption of $g b$ and not some other gene, we compared $g b[K G 07905]$ mutants to animals homozygous for a precise excision. Precise-excision animals contain the same genetic background as the insertion mutant from which they are derived (with the exception of the insertion itself, of course). Therefore, phenotypes present in a transposon insertion mutant but not precise excision are very likely to be caused by the insertion itself and not a background mutation. To generate appropriate precise-excision animals for our study, we mobilized the P-element in P\{SUPor-P\}CG6070[KG07905] using standard methods (Roberts, 1998) and selected for offspring that no longer appeared to contain the $g b[K G 07905]$ insertion in the $g b$ gene. We then sequenced $1 \mathrm{~kb}$ of genomic region surrounding the previously occupied $g b$ [KG07905] insertion site to verify that there was no residual disruption of the $g b$ gene sequence.

As an additional precaution to ensure accurate comparison of hemolymph glutamate concentration between genotypes, we measured the concentration of several hemolymph amino acids 


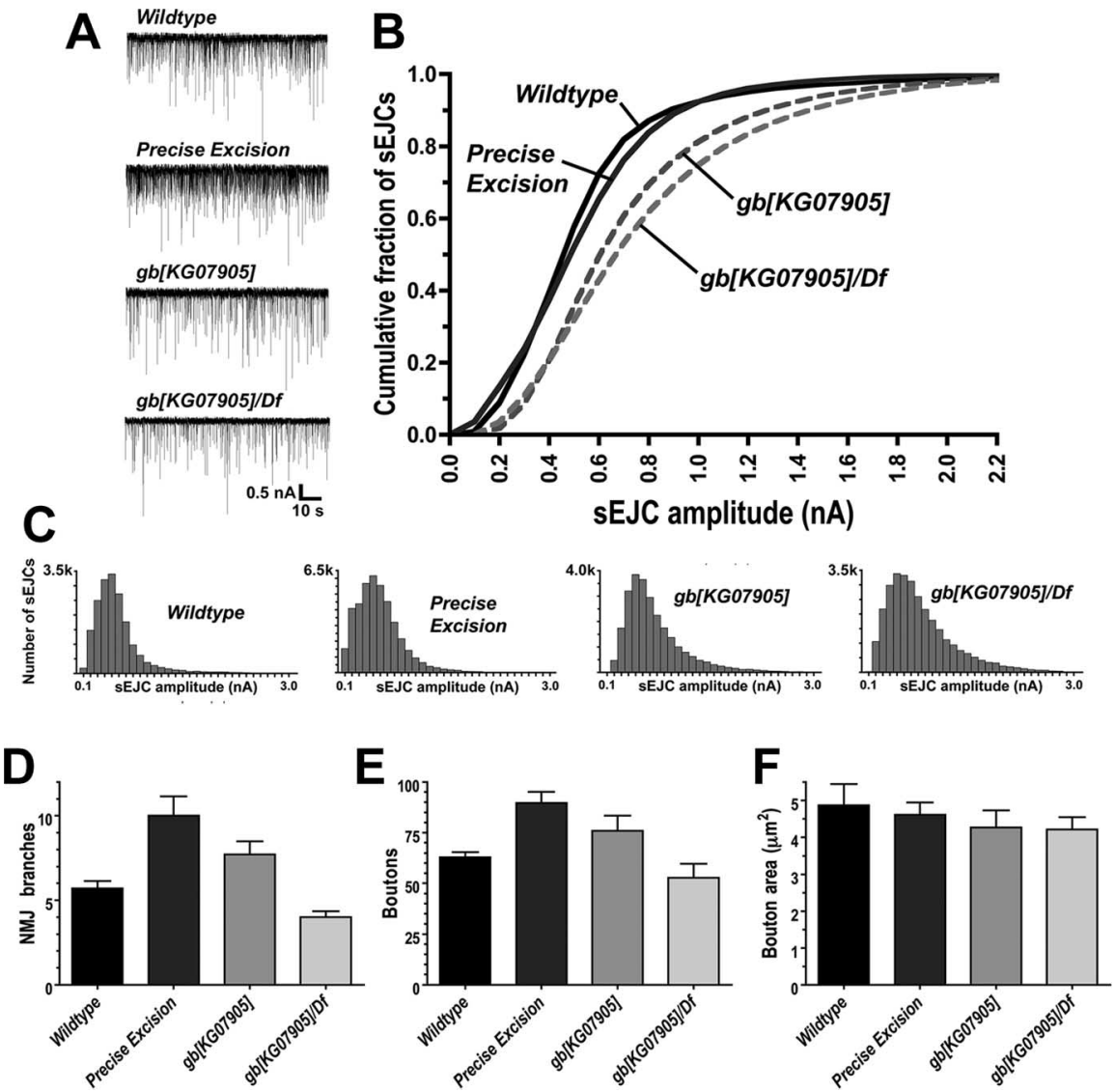

Figure 5. genderblind mutants show an increase in the number of functional postsynaptic glutamate receptors. $\boldsymbol{A}$, Portions of two-electrode voltage-clamp recordings from the L3 muscle 6 NMJ in various genotypes, showing sEJCs (downward deflections). $\boldsymbol{B}$, Cumulative frequency histogram of $s E J$ C amplitudes from various genotypes; a right shift of the curve represents larger synaptic currents ( $n=10-13$ animals, $\sim 18,000-41,000$ events measured per genotype). C, Frequency histograms of sEJC amplitudes from various genotypes. k, 1000. D-F, Number of presynaptic branches $(\boldsymbol{D})$ and presynaptic boutons $(\boldsymbol{E})$ and area of individual boutons $(\boldsymbol{F})$ at the 6/7 NMJ, for various genotypes ( $n=6-8$ animals per genotype). Error bars represent SEM.

simultaneously, including phenylalanine, which is relatively biochemically uncoupled from glutamate but which our preliminary experiments showed occurs at a concentration similar to that of glutamate in hemolymph $(0.84 \mathrm{~F} / \mathrm{E})$. Thus, although there was no a priori or subsequently detectable reason why sample collection efficiency should be different between genotypes, our measured changes are specific to glutamate and are unlikely to be influenced by systematic errors related to sample collection or handling.

Homozygous $g b[K G 07905]$ mutant hemolymph glutamate concentration was approximately one-half that of preciseexcision controls (Fig. 4A), consistent with sequence analysis suggesting that $\mathrm{GB}$ is an essential $\mathrm{xCT}$ subunit and with the conclusion that GB-expressing glia secrete glutamate into the extracellular fluid via GB-based transporters.

\section{Genderblind inhibits glutamate receptor clustering}

It has been shown previously that genetic manipulation of glutamate-metabolizing enzymes can alter the number of postsynaptic glutamate receptors in Drosophila NMJs independent of vesicular glutamate release (Featherstone et al., 2000, 2002). However, a molecular mechanism for nonvesicular glutamate release was never proposed. If GB-based transporters regulate glutamate levels near the NMJ (as suggested by Fig. 2), and nonvesicular glutamate regulates glutamate receptor cluster formation (Featherstone et al., 2000, 2002), then $g b$ mutant NMJs should show a large increase in postsynaptic glutamate receptor abundance.

To test this, we stained NMJs with antiGluRIIA antibodies. As shown in Figure 4, $B$ and $C$, homozygous $g b[K G 07905] \mathrm{mu}-$ tant NMJs showed a $200-300 \%$ increase in postsynaptic glutamate receptor immunoreactivity compared with wild-type and precise-excision controls (Fig. 4B, C). Furthermore, the $g b[K G 07905]$ phenotype was statistically indistinguishable from that measured in $g b[K G 07905] / D f$ animals, suggesting that $g b[K G 07905]$ is a genetic null allele and that the $g b$ mutant phenotype is specifically attributable to disruption of $g b$.

Drosophila NMJs contain two subtypes of ionotropic glutamate receptor: A-type and B-type receptors (Marrus et al., 2004; Chen and Featherstone, 2005; Chen et al., 2005; Featherstone et al., 2005). A-type receptors contain the subunits GluRIIC (also known as GluRIII), GluRIID, GluRIIE, and GluRIIA, but not GluRIIB. B-type receptors contain the subunits GluRIIC, GluRIID, GluRIIE, and GluRIIB, but not GluRIIA. To determine whether B-type receptor abundance might also be regulated by $\mathrm{GB}$, we stained $g b$ mutant NMJs using anti-GluRIIB antibodies. GluRIIB immunoreactivity was also increased in $g b$ mutants (precise-excision relative NMJ GluRIIB immunoreactivity $=100 \pm$ $11 \% ; g b[K G 07905]=235 \pm 20 \%$; $g b[K G 07905] / D f=211 \pm 43 \% ; n=4-5$; $p<0.05)$. Thus, both A- and B-type glutamate receptors are strongly regulated by

GB function in vivo.

If GB regulates NMJ glutamate receptor abundance indirectly via glutamate, we should be able to rescue the $g b$ mutant receptor phenotype by "correcting" extracellular glutamate concentration independent of GB. To test this, we cultured semi-intact $g b$ and GOT mutant larvae in wild-type levels of hemolymph glutamate (2 mM). Semi-intact Drosophila larvae can be kept alive in culture medium for days (Ball et al., 2003), allowing relatively long-term pharmacological manipulations. GOT (Enzyme Commission 2.6.1.1) is an enzyme required for cytoplasmic glutamate synthesis in Drosophila (Chase and Kankel, 1987; Caggese et al., 1994). In GOT mutants, glutamate synthesis is impaired, and NMJs show a large increase in postsynaptic glutamate receptor number (Fig. 4 B) (Chase and Kankel, 1987; Caggese et al., 1994; Featherstone et al., 2002). Thus, GOT mutants are a way of mimicking the $g b$ mutant phenotype in a confirmed glutamate-dependent way. As shown in Figure $4 B$, normal levels of extracellular glutamate completely rescued both the $g b$ and GOT mutant receptor phenotypes, consistent with the idea that the glutamate receptor changes in both $g b$ and GOT mutants are attributable to decreases in extracellular glutamate.

We also examined $g b$ mutant NMJs electrophysiologically (Fig. $5 A-C$ ). As predicted by our immunocytochemical results, the mean amplitude of spontaneous excitatory junction currents (sEJCs) was almost doubled in $g b$ mutants (Fig. 5A-C). Thus, both immunocytochemistry and electrophysiology revealed a 
A

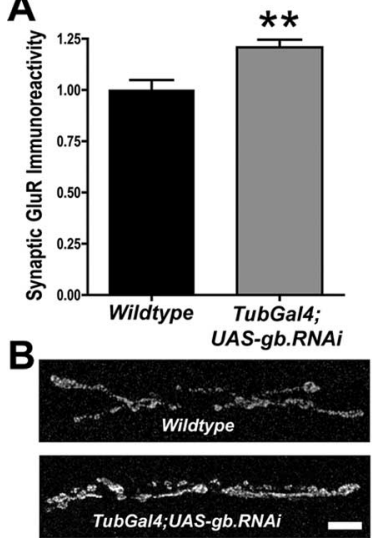

C

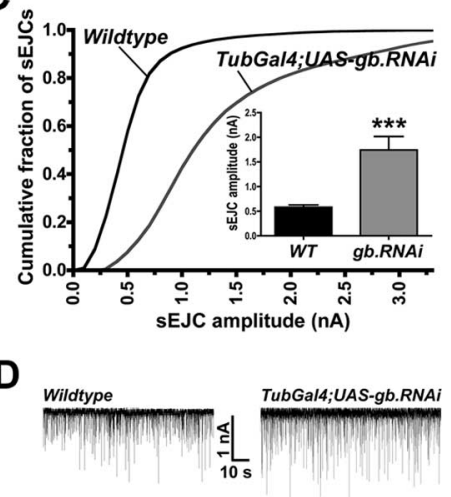

Figure 6. Transgenic expression of genderblind RNAi phenocopies $g b$ mutants. A, Relative synaptic GluRIIA immunoreactivity (as in Fig. $4 B$ ) after knockdown of $g b$ by ubiquitous expression of $g b$ RNAi. B, Representative GluRllA staining (as in Fig. 4C). Scale bar, $10 \mu \mathrm{m}$. C, Cumulative frequency histograms of sEJC amplitudes (as in Fig. 5B). D, Representative electrophysiological recordings (as in Fig. 5A; $n=10-13$ animals). Error bars represent SEM.

large increase in postsynaptic glutamate receptor number after disruption of GB. $g b$ mutants showed no change in sEJC frequency compared with wild-type controls. However, interestingly, precise-excision animals showed significantly higher sEJC frequencies than other genotypes (precise excision $=4.3 \pm 0.6$ $\mathrm{Hz} ; \mathrm{WT}=2.3 \pm 0.3 \mathrm{~Hz} ; g b[K G 07905]=2.4 \pm 0.3 \mathrm{~Hz}$; $g b[K G 07905] / \mathrm{Df}=2.2 \pm 0.3 \mathrm{~Hz} ; n=10-13)$. Precise-excision animals also showed a significant increase in NMJ branches and bouton number compared with other genotypes (Fig. 5D-F), consistent with the fact that increased larval NMJ growth is known to be associated with increased synaptic activity (Budnik et al., 1990; Gramates and Budnik, 1999). Nevertheless, preciseexcision animals showed no change in postsynaptic glutamate receptor abundance compared with wild-type controls, consistent with the idea that vesicular glutamate release is relatively unimportant for regulation of glutamate receptor abundance in Drosophila NMJs (Featherstone et al., 2002).

We also generated Drosophila carrying $g b$-specific RNAi transgenes. Ubiquitous expression of $g b$ RNAi (TubGal4;UAS- $g b . R N A i$ ) significantly knocked down $g b$ RNA and protein levels in larvae (supplemental material, available at www.jneurosci.org) and qualitatively phenocopied the increase in postsynaptic glutamate receptors observed in $g b$ mutants (Fig. 6). Expression of $g b$ RNAi did not significantly alter sEJC frequency, compared with WT controls $(\mathrm{WT}=2.3 \pm 0.3 \mathrm{~Hz} ; g b \mathrm{RNAi}=3.2 \pm 0.5 \mathrm{~Hz} ; n=13)$.

These data demonstrate that GB-based transporters are very strong regulators of postsynaptic ionotropic glutamate receptor abundance. Most likely, this regulation occurs indirectly, via regulation of extracellular ambient glutamate concentration. We explore this possibility further below.

\section{Ambient extracellular glutamate suppresses postsynaptic glutamate receptor localization via desensitization} To explore the hypothesis that GB regulates glutamate receptor abundance via regulation of ambient extracellular glutamate, we performed more pharmacological experiments on cultured semiintact larvae. As shown in Figure 7, $A$ and $B$, and predicted by our model for GB function, the concentration of glutamate in the culture medium bathing larval NMJs had a strong effect on postsynaptic abundance of both A- and B-type receptors. Specifically, abnormally low glutamate $(0 \mathrm{~mm})$ caused a large (300-
$500 \%$ ) increase in postsynaptic A- and B-type glutamate receptor immunoreactivity after $24 \mathrm{~h}$, compared with NMJs fixed immediately after dissection ("baseline"). In the range of 2-10 mM glutamate, which matches measurements of wild-type hemolymph glutamate concentration (McDonald, 1975; Echalier, 1997; Pierce et al., 1999), the number of postsynaptic glutamate receptors remained near normal levels for at least $24 \mathrm{~h}$ (Fig. 7B). These results suggest that normal glutamate receptor abundance in Drosophila NMJs depends on normal (2-10 mM) perisynaptic glutamate levels; too little glutamate results in too many postsynaptic glutamate receptors. These results are qualitatively and quantitatively consistent with the $g b$ mutant phenotype, in which extracellular glutamate dropped to approximately one-half of normal (from $\sim 2$ to $\sim 1 \mathrm{~mm}$ ) (Fig. $4 A$ ) and postsynaptic receptor number doubled (Figs. 4, 5).

Application of $10 \mathrm{~mm} \gamma$-D-glutamylglycine ( $\gamma$-DGG), a competitive glutamate receptor antagonist (Pawlu et al., 2004), completely blocked the effect of glutamate (Fig. 7C), consistent with the idea that regulation of postsynaptic glutamate receptor abundance by glutamate requires glutamate binding to the receptors themselves [no metabotropic glutamate receptors are expressed in Drosophila larval muscle (Bogdanik et al., 2004)]. Similarly, application of $10 \mathrm{~mm}$ aspartic acid instead of glutamate had no effect on postsynaptic glutamate receptor number (Fig. 7C). Loss of glutamate receptors after exposure to glutamate was relatively specific; we observed no decrease in NMJ size or bouton number after culturing animals in glutamate (data not shown). We also observed no change in levels of Fasciclin II (Fig. 7D), another transmembrane protein tightly localized to Drosophila NMJs (Schuster et al., 1996).

To determine how long glutamate-dependent changes in postsynaptic glutamate receptor abundance took, we fixed and stained NMJs after variable lengths of time in culture and after variable lengths of glutamate exposure (Fig. 8). Synaptic GluRIIA (Fig. 8A) and GluRIIB (Fig. 8C) immunoreactivity both increased slightly during the first $6 \mathrm{~h}$ in culture, whether the culture medium contained 0 or $10 \mathrm{~mm}$ glutamate. After $6 \mathrm{~h}$, however, NMJs cultured in $0 \mathrm{~mm}$ continued to accumulate glutamate receptors, whereas NMJs cultured in $10 \mathrm{~mm}$ glutamate did not accumulate either GluRIIA or GluRIIB (Fig. 8A,C). Similar results were observed using GFP-tagged GluRIIA (Rasse et al., 2005) watched over time (data not shown). To test whether these changes were dependent on changes in glutamate and not time in culture, we switched the culture media from 10 to $0 \mathrm{~mm}$ glutamate after $12 \mathrm{~h}$ and then fixed and stained NMJs at $24 \mathrm{~h}$ (Fig. $8 B, D)$. As expected if changes in receptor abundance depended on glutamate and not time in culture, exposure to $0 \mathrm{~mm}$ glutamate between hours 12 and 24 in culture caused a rise in postsynaptic glutamate receptor abundance equal to that observed during exposure to $0 \mathrm{~mm}$ glutamate between hours 0 and 12 in culture (Fig. $8 \mathrm{~A}, \mathrm{C}$ ). Thus, we conclude that glutamate suppresses synaptic accumulation of glutamate receptors. In the absence of this suppression, glutamate receptors accumulate at synapses with a time course similar to that previously observed during development of intact larvae (Rasse et al., 2005).

How might binding of glutamate to ionotropic receptors suppress accumulation of these receptors at synapses? Ambient extracellular glutamate almost certainly shifts some glutamate receptors into a persistently desensitized state. The relatively large conformational change represented by desensitization (Nakagawa et al., 2005; Armstrong et al., 2006) could easily alter interactions between receptors and intracellular scaffolding/localization proteins or regulate accessibility of phosphorylation sites 
A
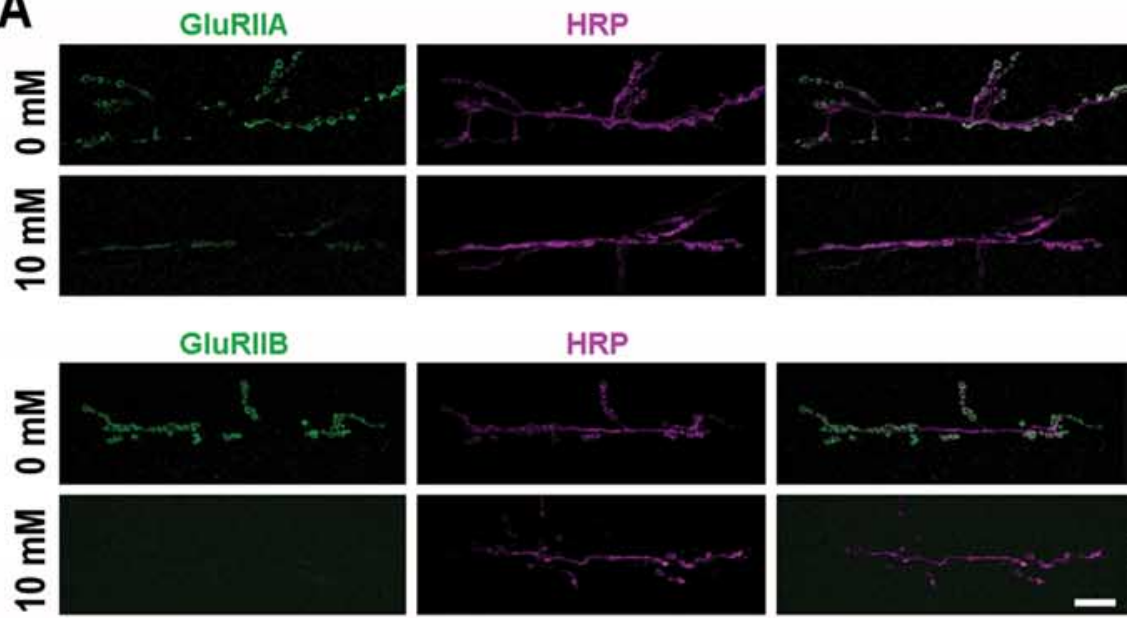

B

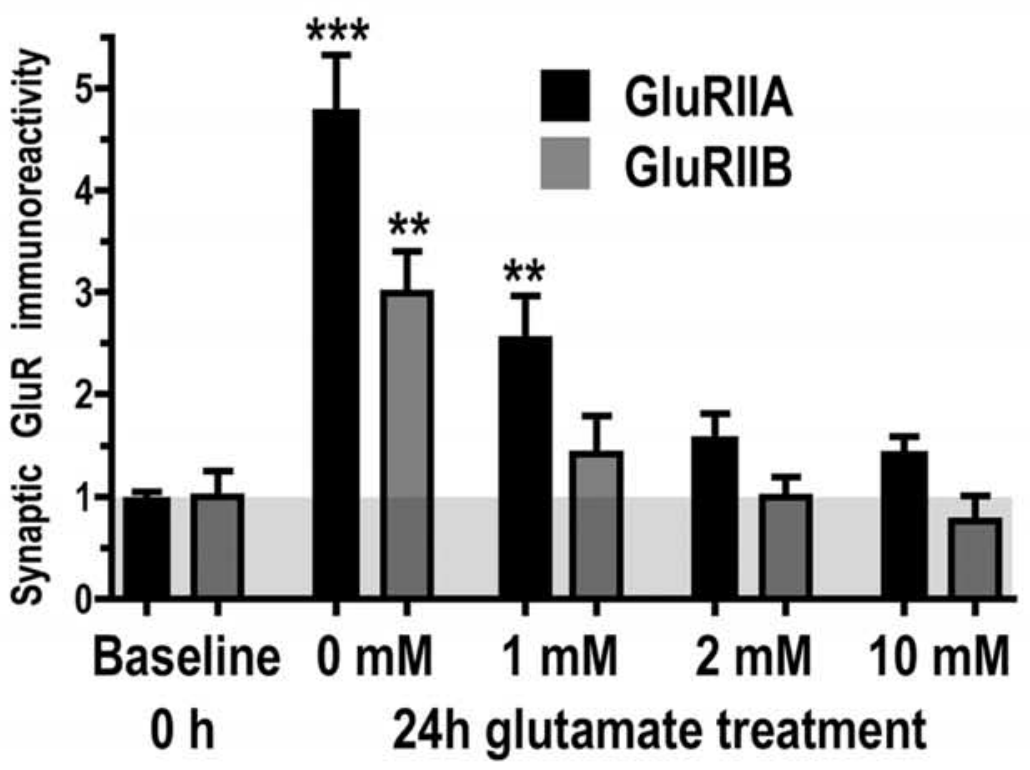

C

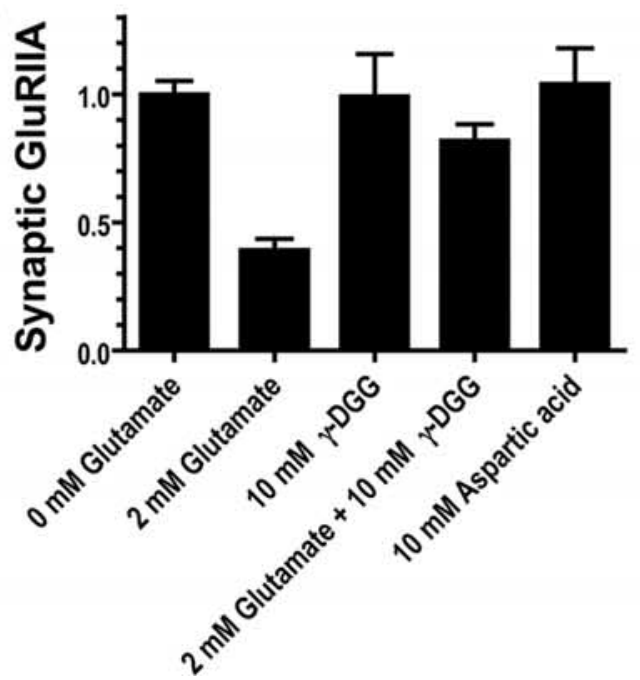

D

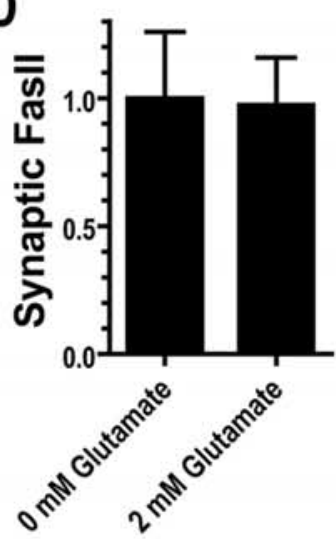

Figure 7. Glutamate negatively regulates postsynaptic glutamate receptor abundance. $A$, Confocal micrographs of WT 6/7 NMJs cultured for $24 \mathrm{~h}$ in culture medium containing 0 or $10 \mathrm{~mm}$ glutamate and then fixed and stained with antibodies against glutamate receptor subunits GluRIIA (top, green) or GluRIIB (bottom, green) and the neuronal membrane marker anti-HRP (magenta). Scale bar, $10 \mu \mathrm{m}$. B, Postsynaptic 6/7 NMJ glutamate receptor immunofluorescence in larvae cultured in medium containing various amounts of glutamate. A large increase in postsynaptic glutamate receptors was measured when that control trafficking. To test whether glutamate-dependent changes in postsynaptic glutamate receptor localization depend on desensitization, we cultured NMJs in both glutamate and concanavalin A, an inhibitor of insect glutamate receptor desensitization (Mathers and Usherwood, 1976a,b, 1978) (Fig. 9A-C). As shown in Figure 9, $B$ and $C, 10 \mathrm{~mm}$ concanavalin A completely blocked suppression of glutamate receptor clustering by glutamate. Application of two less-potent modulators of ionotropic glutamate receptor desensitization, cyclothiazide and PEPA, reduced suppression of postsynaptic glutamate receptor localization consonant with their ability to regulate Drosophila NMJ glutamate receptor current desensitization as measured electrophysiologically from increases in EJC decayphase time constants after drug application (Fig. 9D). We conclude from these data that glutamate-mediated suppression of synaptic glutamate receptor accumulation depends on receptor desensitization.

\section{Discussion}

Using bioinformatics, we identified a highly conserved Drosophila xCT gene, which we named genderblind. Immunocytochemistry and confocal microscopy on animals with transgenically marked cell subtypes revealed that GB is expressed in a previously undescribed subset of central and peripheral glia. HPLC demonstrates that $g b$ mutants have approximately onehalf of normal extracellular free glutamate, consistent with the prediction that $\mathrm{xCT}$ transporters are critical regulators of extracellular glutamate in vivo. $g b$ mutants also showed a 200-300\% increase in postsynaptic glutamate receptor abundance, as measured immunocytochemically and electrophysiologically. This phenotype was duplicated in flies transgenically expressing $g b$ RNAi and completely rescued by culturing mutant synapses in wild-type ( $2 \mathrm{~mm}$ ) levels of glutamate, consonant with the idea that GB regulates glutamate receptor clustering via regulation of extracellular glutamate. To confirm this idea and explore the mecha-

\footnotetext{
$\leftarrow$

larvae were cultured for $24 \mathrm{~h}$ in medium containing $<2 \mathrm{~mm}$ glutamate ( $n=8-16$ animals per genotype per assay). $C_{\text {, }}$ Glutamate-dependent loss of postsynaptic glutamate receptors is blocked by $10 \mathrm{~mm} \gamma$-DGG, a competitive glutamate receptor antagonist, and does not occur in response to $10 \mathrm{~mm}$ aspartic acid ( $n=5-23$ animals per genotype per assay). $\boldsymbol{D}$, Glutamate does not trigger loss of the presynaptic and postsynaptic transmembrane protein fasciclin II (Fasll; $n=$ 6-8 animals). Error bars represent SEM.
} 
nism, we cultured semi-intact preparations in variable concentrations of glutamate, for varying lengths of time, and in combination with several pharmacological agents. The results of these experiments suggest that ambient extracellular glutamate persistently desensitizes glutamate receptors to suppress synaptic clustering. Together, our results suggest that (1) glial $\mathrm{xCT}$ transporters secrete glutamate, (2) this glutamate constitutively desensitizes receptors, and (3) desensitization somehow inhibits glutamate receptor clustering at synapses. This is a novel mechanism for regulation of glutamate receptor localization and a new role for $\mathrm{xCT}$ transporters.

The primary physiological role of $\mathrm{xCT}$ transporters remains controversial. Although $\mathrm{xCT}$ transporters mediate 1:1 exchange between extracellular cystine and intracellular glutamate, glutamate excretion is generally ignored, and xCT transporters are often assumed to function primarily as a cystine-uptake mechanism for glutathione synthesis and protection from oxidative stress (Bannai and Ishii, 1982; Bannai et al., 1984; Christensen, 1990; Shih et al., 2006). However, this bias ignores several important facts: (1) xCT transporters also export glutamate. (2) Mammalian brain xCT appears most abundant in "border areas between the brain proper and periphery" (Burdo et al., 2006), specifically "several regions facing the CSF," including ventricle walls and meninges (Sato et al., 2002), consistent with the idea that $\mathrm{xCT}$ transporters are important for regulation of free glutamate content of CSF but not for cystine uptake in all brain cells. (3) Mammalian xCT transporters appear to be dispensable for cystine uptake and glutathione synthesis (Chung et al., 2005). Instead, glutathione synthesis in neurons and glia may be regulated by excitatory amino acid transport (EAAT) family proteins. EAATs are best known as sodium-dependent transporters for glutamate uptake, but EAATs also efficiently import cysteine, the reduced form of cystine used in glutathione synthesis (Chen et al., 2000; Flynn and McBean, 2000; Danbolt, 2001; McBean, 2002; Chen and Swanson, 2003; Chung et al., 2005). In agreement, overexpression of Drosophila gb (Tub-Gal4;UAS-gb) causes shortened lifespan and neurodegeneration (our unpublished results), consistent with increased glutamate secretion but the exact opposite phenotype that one would expect if the role of GB were cystine uptake for neuroprotection. (4) Microdialysis of rat brains with inhibitors of xCT function leads to a decrease in nonvesicular glutamate secretion (Baker et al., 2002).

Accordingly, we argue that glutamate export by xCT transporters is at least as important as cystine import, particularly in the nervous system. Full acceptance of this idea, however, requires one to accept the idea that $\mathrm{xCT}$ transporters maintain ambient extracellular glutamate in the nervous system for good reasons and that extracellular glutamate in the brain is not merely a potentially pathological byproduct of glutamatergic transmission. Our data suggest that ambient extracellular glutamate regulates constitutive receptor desensitization for control of synaptic glutamate receptor abundance.

A link between glutamate receptor desensitization and clustering has not previously been demonstrated. It is well known that desensitization functionally eliminates glutamate receptors on a short time scale (tens to hundreds of milliseconds). Our data suggest that constitutive desensitization is, on a longer time scale (hours), also associated with removal of receptors from the synapse. The $\mathrm{EC}_{50}$ for activation of Drosophila larval muscle glutamate receptors is $\sim 2 \mathrm{mM}$ (Heckmann et al., 1996), and significant numbers of receptors can be desensitized at considerably lower concentrations (Heckmann and Dudel, 1997). Because $2 \mathrm{~mm}$ is near the concentration of glutamate bathing NMJ receptors in vivo (McDonald, 1975; Echalier, 1997; Pierce et al., 1999) (our unpublished results), we must conclude that one-half or more of Drosophila larval muscle glutamate receptors are constitutively desensitized, and therefore delocalized, in vivo. This conclusion is consistent with the $200-300 \%$ increase in postsynaptic glutamate receptor abundance that we observe after switching NMJs to culture media containing $0 \mathrm{~mm}$ glutamate.

At first, the idea that many glutamate receptors should be desensitized (and subsequently delocalized) in vivo seems surprising. However, constitutive desensitization (and subsequent delocalization) of ligand-gated ion channels by ambient ligand is analogous to constitutive inactivation of voltage-gated ion channels by resting membrane potential. Constitutive inactivation of voltage-gated channels is a common and important regulator of membrane excitability. For example, at a typical rat skeletal muscle resting potential of $-90 \mathrm{mV}$, approximately two-thirds of rat skm-1 skeletal muscle sodium channels are inactivated (Ruff et al., 1988; Featherstone et al., 1996). As a result, only one-third of channels in the membrane are normally available for generation of action potentials. However, if resting membrane potential is modified or the voltage dependence of sodium channel inactivation is slightly shifted by (for example) channel phosphorylation, then the number of functionally available sodium channels in the membrane can change quickly and dramatically, with consequent large effects on cell excitability (Catterall, 1999). In the case of glutamate receptors, the number of functionally available re- 
A
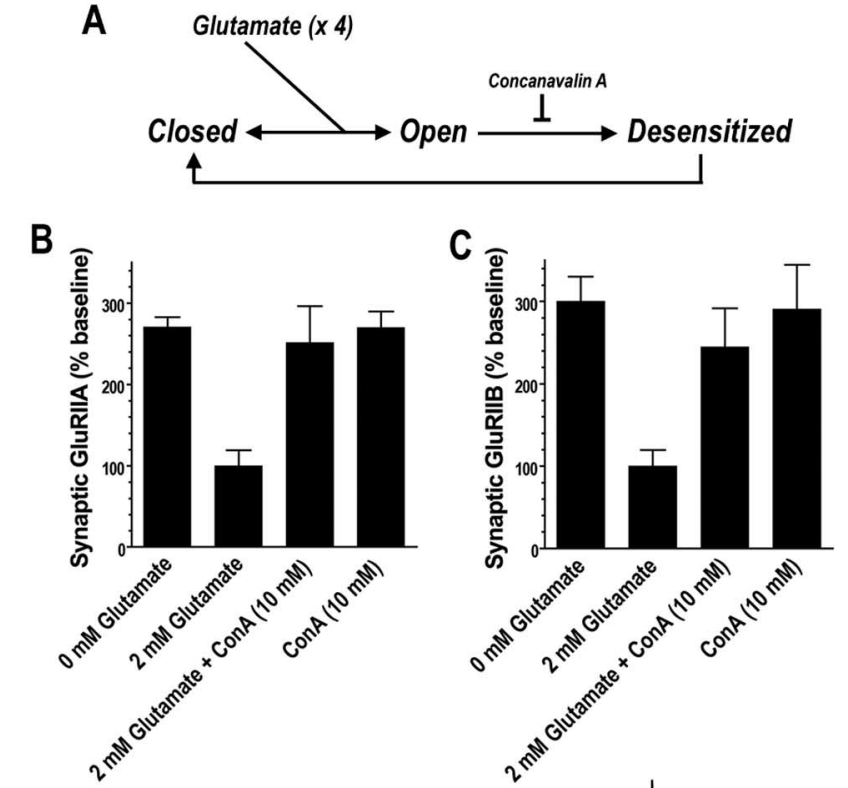

D
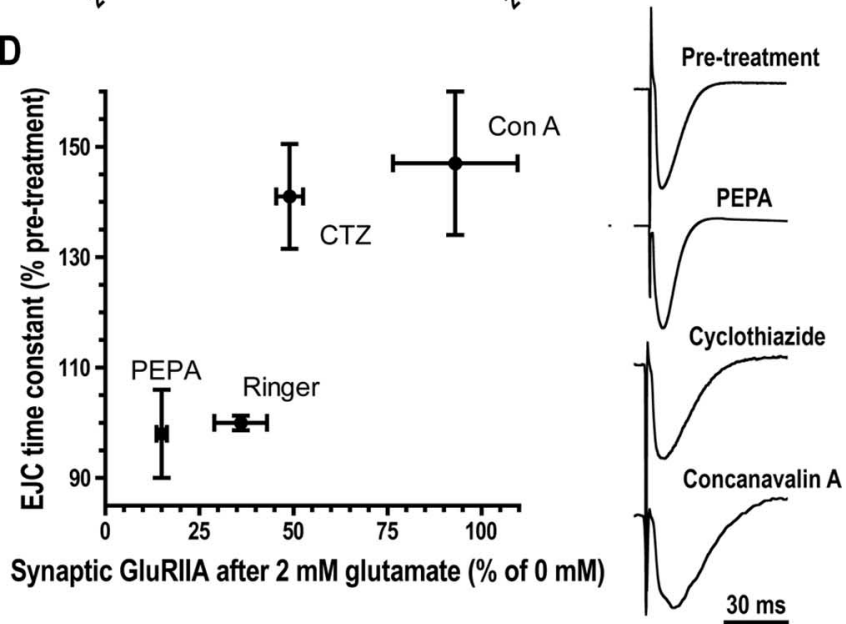

Figure 9. Glutamate suppresses glutamate receptor localization via a desensitizationdependent mechanism. $\boldsymbol{A}$, Diagrammatic summary of ionotropic glutamate receptor gating: binding of glutamate to each subunit causes receptor pore opening, followed by desensitization. $\boldsymbol{B}$, Glutamate-dependent loss of A-type postsynaptic glutamate receptors is blocked by 10 $\mathrm{mm}$ concanavalin A (ConA), a desensitization inhibitor ( $n=5-20$ animals). C, Glutamatedependent loss of B-type postsynaptic glutamate receptors is blocked by $10 \mathrm{~mm}$ concanavalin $\mathrm{A}$ $(n=5-20$ animals). $\boldsymbol{D}$, Different pharmacological agents block glutamate-dependent loss of synaptic GluRIIA in inverse proportion to the degree with which the agents inhibit desensitization ( $n=4-20$ animals). The ability of each agent to inhibit desensitization was quantified by measuring the increase in EJC falling phase time constants caused by drug application. Sample EJC recordings are shown on the right.

ceptors at a synapse, and therefore synaptic strength, could similarly be quickly and effectively altered by relatively minor changes in ambient glutamate levels (perhaps because of regulation of xCT-mediated transport) or changes in the concentration dependence of receptor desensitization as a result of (for example) receptor phosphorylation. These possibilities have not been explored.

A physiological role for ambient extracellular glutamate also has medical implications. Abnormal levels of CSF glutamate have been linked to a variety of human neurodevelopmental and neurodegenerative disorders, including anxiety/stress-related disorders (Cortese and Phan, 2005; Porrino et al., 2005; Swanson et al., 2005), Rett syndrome (Hamberger et al., 1992; Riikonen, 2003), autism (Moreno-Fuenmayor et al., 1996; Aldred et al., 2003), and all forms (both familial and sporadic) of amyotrophic lateral sclerosis (Rothstein et al., 1990, 1992; Spreux-Varoquaux et al., 2002; Cid et al., 2003). Furthermore, xCT and 4F2hc have specifically been implicated in development, behavior, and disease. For example, lysinuric protein intolerance, a recessive disorder characterized by severe mental retardation, is caused by mutations in the human xCT gene SLC7A7 [solute carrier family 7 (cationic amino acid transporter, $y+$ system), member 7] (Lauteala et al., 1998; Torrents et al., 1999; Inlow and Restifo, 2004). Similarly, $4 \mathrm{~F} 2 \mathrm{hc}$ is required for tumor transformation in human cancers (Henderson et al., 2004), and inhibition of system $\mathrm{x}_{\mathrm{c}}^{-}$disrupts primary brain tumor growth (Chung et al., 2005). Finally, human $\mathrm{xCT}$ protein was recently identified as the fusion-entry receptor for Kaposi's sarcoma-associated herpes virus (Kaleeba and Berger, 2006). Not surprisingly, therefore, extracellular glutamate and $\mathrm{xCT}$ transporters are beginning to be targeted for pharmacological inhibition. Our results suggest that pharmacological inhibition of $\mathrm{xCT}$ transport could considerably ameliorate neuropathologies exacerbated by extracellular glutamate but raise the caveat that tampering with extracellular glutamate could have unexpected developmental and/or psychotropic effects.

\section{References}

Aldred S, Moore KM, Fitzgerald M, Waring RH (2003) Plasma amino acid levels in children with autism and their families. J Autism Dev Disord 33:93-97.

Armstrong N, Jasti J, Beich-Frandsen M, Gouaux E (2006) Measurement of conformational changes accompanying desensitization in an ionotropic glutamate receptor. Cell 127:85-97.

Baker DA, Xi ZX, Shen H, Swanson CJ, Kalivas PW (2002) The origin and neuronal function of in vivo nonsynaptic glutamate. J Neurosci 22:9134-9141.

Ball R, Xing B, Bonner P, Shearer J, Cooper RL (2003) Long-term in vitro maintenance of neuromuscular junction activity of Drosophila larvae. Comp Biochem Physiol A Mol Integr Physiol 134:247-255.

Banerjee S, Pillai AM, Paik R, Li J, Bhat MA (2006) Axonal ensheathment and septate junction formation in the peripheral nervous system of Drosophila. J Neurosci 26:3319-3329.

Bannai S, Ishii T (1982) Transport of cystine and cysteine and cell growth in cultured human diploid fibroblasts: effect of glutamate and homocysteate. J Cell Physiol 112:265-272.

Bannai S, Christensen HN, Vadgama JV, Ellory JC, Englesberg E, Guidotti GG, Gazzola GC, Kilberg MS, Lajtha A, Sacktor B, Sepúlveda FV, Young JD, Yudilevich D, Mann G (1984) Amino acid transport systems. Nature 311:308.

Bellen HJ, Levis RW, Liao G, He Y, Carlson JW, Tsang G, Evans-Holm M, Hiesinger PR, Schulze KL, Rubin GM, Hoskins RA, Spradling AC (2004) The BDGP gene disruption project: single transposon insertions associated with $40 \%$ of Drosophila genes. Genetics 167:761-781.

Bogdanik L, Mohrmann R, Ramaekers A, Bockaert J, Grau Y, Broadie K, Parmentier ML (2004) The Drosophila metabotropic glutamate receptor DmGluRA regulates activity-dependent synaptic facilitation and fine synaptic morphology. J Neurosci 24:9105-9116.

Brand AH, Perrimon N (1993) Targeted gene expression as a means of altering cell fates and generating dominant phenotypes. Development 118:401-415.

Brink DL, Jusiak B, Auld V (2005) Peripheral glial cells at the larval neuromuscular junction of Drosophila. Soc Neurosci Abstr 31:973.6.

Budnik V, Zhong Y, Wu CF (1990) Morphological plasticity of motor axons in Drosophila mutants with altered excitability. J Neurosci 10:3754-3768.

Burdo J, Dargusch R, Schubert D (2006) Distribution of the cystine/glutamate antiporter system xc- in the brain, kidney, and duodenum. J Histochem Cytochem 54:549-557.

Caggese C, Barsanti P, Viggiano L, Bozzetti MP, Caizzi R (1994) Genetic, molecular and developmental analysis of the glutamine synthetase isozymes of Drosophila melanogaster. Genetica 94:275-281.

Catterall WA (1999) Molecular properties of brain sodium channels: an important target for anticonvulsant drugs. Adv Neurol 79:441-456. 
Chase BA, Kankel DR (1987) A genetic analysis of glutamatergic function in Drosophila. J Neurobiol 18:15-41.

Chen K, Featherstone DE (2005) Discs-large (DLG) is clustered by presynaptic innervation and regulates postsynaptic glutamate receptor subunit composition in Drosophila. BMC Biol 3:1.

Chen K, Merino C, Sigrist SJ, Featherstone DE (2005) The 4.1 protein coracle mediates subunit-selective anchoring of Drosophila glutamate receptors to the postsynaptic actin cytoskeleton. J Neurosci 25:6667-6675.

Chen L, Chetkovich DM, Petralia RS, Sweeney NT, Kawasaki Y, Wenthold RJ, Bredt DS, Nicoll RA (2000) Stargazin regulates synaptic targeting of AMPA receptors by two distinct mechanisms. Nature 408:936-943.

Chen Y, Swanson RA (2003) The glutamate transporters EAAT2 and EAAT3 mediate cysteine uptake in cortical neuron cultures. J Neurochem 84:1332-1339.

Chillaron J, Roca R, Valencia A, Zorzano A, Palacin M (2001) Heteromeric amino acid transporters: biochemistry, genetics, and physiology. Am J Physiol Renal Physiol 281:F995-F1018.

Christensen HN (1990) Role of amino acid transport and countertransport in nutrition and metabolism. Physiol Rev 70:43-77.

Chung WJ, Lyons SA, Nelson GM, Hamza H, Gladson CL, Gillespie GY, Sontheimer H (2005) Inhibition of cystine uptake disrupts the growth of primary brain tumors. J Neurosci 25:7101-7110.

Cid C, Alvarez-Cermeno JC, Regidor I, Salinas M, Alcazar A (2003) Low concentrations of glutamate induce apoptosis in cultured neurons: implications for amyotrophic lateral sclerosis. J Neurol Sci 206:91-95.

Cortese BM, Phan KL (2005) The role of glutamate in anxiety and related disorders. CNS Spectr 10:820-830.

Danbolt NC (2001) Glutamate uptake. Prog Neurobiol 65:1-105.

Echalier G (1997) Composition of the body fluid of Drosophila and the design of culture media for Drosophila cells. In: Drosophila cells in culture, pp 1-67. New York: Academic.

Featherstone DE, Richmond JE, Ruben PC (1996) Interaction between fast and slow inactivation in Skm1 sodium channels. Biophys J 71:3098-3109.

Featherstone DE, Rushton EM, Hilderbrand-Chae M, Phillips AM, Jackson FR, Broadie K (2000) Presynaptic glutamic acid decarboxylase is required for induction of the postsynaptic receptor field at a glutamatergic synapse. Neuron 27:71-84.

Featherstone DE, Rushton E, Broadie K (2002) Developmental regulation of glutamate receptor field size by nonvesicular glutamate release. Nat Neurosci 5:141-146.

Featherstone DE, Rushton E, Rohrbough J, Liebl F, Karr J, Sheng Q, Rodesch CK, Broadie K (2005) An essential Drosophila glutamate receptor subunit that functions in both central neuropil and neuromuscular junction. J Neurosci 25:3199-3208.

Flynn J, McBean GJ (2000) Kinetic and pharmacological analysis of L-[35S]cystine transport into rat brain synaptosomes. Neurochem Int 36:513-521.

Gramates LS, Budnik V (1999) Assembly and maturation of the Drosophila larval neuromuscular junction. Int Rev Neurobiol 43:93-117.

Grunwald ME, Mellem JE, Strutz N, Maricq AV, Kaplan JM (2004) Clathrin-mediated endocytosis is required for compensatory regulation of GLR-1 glutamate receptors after activity blockade. Proc Natl Acad Sci USA 101:3190-3195.

Hamberger A, Gillberg C, Palm A, Hagberg B (1992) Elevated CSF glutamate in Rett syndrome. Neuropediatrics 23:212-213.

Heckmann M, Dudel J (1997) Desensitization and resensitization kinetics of glutamate receptor channels from Drosophila larval muscle. Biophys J 72:2160-2169.

Heckmann M, Parzefall F, Dudel J (1996) Activation kinetics of glutamate receptor channels from wild-type Drosophila muscle. Pflügers Arch 432:1023-1029.

Henderson NC, Collis EA, Mackinnon AC, Simpson KJ, Haslett C, Zent R, Ginsberg M, Sethi T (2004) CD98hc (SLC3A2) interaction with beta 1 integrins is required for transformation. J Biol Chem 279:54731-54741.

Hosoya K, Tomi M, Ohtsuki S, Takanaga H, Saeki S, Kanai Y, Endou H, Naito M, Tsuruo T, Terasaki T (2002) Enhancement of L-cystine transport activity and its relation to $\mathrm{xCT}$ gene induction at the blood-brain barrier by diethyl maleate treatment. J Pharmacol Exp Ther 302:225-231.

Inlow JK, Restifo LL (2004) Molecular and comparative genetics of mental retardation. Genetics 166:835-881.

Jahn K, Bufler J, Franke C (1998) Kinetics of AMPA-type glutamate receptor channels in rat caudate-putamen neurones show a wide range of de- sensitization but distinct recovery characteristics. Eur J Neurosci 10:664-672.

Kaleeba JA, Berger EA (2006) Kaposi's sarcoma-associated herpesvirus fusion-entry receptor: cystine transporter xCT. Science 311:1921-1924.

Kanai Y, Endou H (2001) Heterodimeric amino acid transporters: molecular biology and pathological and pharmacological relevance. Curr Drug Metab 2:339-354.

Kearney JB, Wheeler SR, Estes P, Parente B, Crews ST (2004) Gene expression profiling of the developing Drosophila CNS midline cells. Dev Biol 275:473-492.

Kim JY, Kanai Y, Chairoungdua A, Cha SH, Matsuo H, Kim DK, Inatomi J, Sawa H, Ida Y, Endou H (2001) Human cystine/glutamate transporter: cDNA cloning and upregulation by oxidative stress in glioma cells. Biochim Biophys Acta 1512:335-344.

Lauteala T, Mykkanen J, Sperandeo MP, Gasparini P, Savontaus ML, Simell O, Andria G, Sebastio G, Aula P (1998) Genetic homogeneity of lysinuric protein intolerance. Eur J Hum Genet 6:612-615.

Lee YS, Carthew RW (2003) Making a better RNAi vector for Drosophila: use of intron spacers. Methods 30:322-329.

Lerma J, Paternain AV, Rodriguez-Moreno A, Lopez-Garcia JC (2001) Molecular physiology of kainate receptors. Physiol Rev 81:971-998.

Liebl FL, Featherstone DE (2005) Genes involved in Drosophila glutamate receptor expression and localization. BMC Neurosci 6:44.

Liebl FL, Chen K, Karr J, Sheng Q, Featherstone DE (2005) Increased synaptic microtubules and altered synapse development in Drosophila sec8 mutants. BMC Biol 3:27.

Liebl FL, Werner KM, Sheng Q, Karr JE, McCabe BD, Featherstone DE (2006) Genome-wide P-element screen for Drosophila synaptogenesis mutants. J Neurobiol 66:332-347.

Lissin DV, Carroll RC, Nicoll RA, Malenka RC, von Zastrow M (1999) Rapid, activation-induced redistribution of ionotropic glutamate receptors in cultured hippocampal neurons. J Neurosci [Erratum (1999) 19: 3275] 19:1263-1272.

Marrus SB, Portman SL, Allen MJ, Moffat KG, DiAntonio A (2004) Differential localization of glutamate receptor subunits at the Drosophila neuromuscular junction. J Neurosci 24:1406-1415.

Mathers DA, Usherwood PN (1976a) Concanavalin A blocks desensitisation of glutamate receptors on insect muscle fibres. Nature 259:409-411.

Mathers DA, Usherwood PN (1976b) Proceedings: blockade of desensitization of glutamate receptors on insect muscle by concanavalin A. J Physiol (Lond) 258:104P-105P.

Mathers DA, Usherwood PN (1978) Effects of concanavalin A on junctional and extrajunctional L-glutamate receptors on locust skeletal muscle fibres. Comp Biochem Physiol C 59:151-155.

McBean GJ (2002) Cerebral cystine uptake: a tale of two transporters. Trends Pharmacol Sci 23:299-302.

McDonald TJ (1975) Neuromuscular pharmacology of insects. Annu Rev Entomol 20:151-166.

Moreno-Fuenmayor H, Borjas L, Arrieta A, Valera V, Socorro-Candanoza L (1996) Plasma excitatory amino acids in autism. Invest Clin 37:113-128.

Nahum-Levy R, Lipinski D, Shavit S, Benveniste M (2001) Desensitization of NMDA receptor channels is modulated by glutamate agonists. Biophys J 80:2152-2166.

Nakagawa T, Cheng Y, Ramm E, Sheng M, Walz T (2005) Structure and different conformational states of native AMPA receptor complexes. Nature 433:545-549.

Olney JW, Price MT, Salles KS, Labruyere J, Ryerson R, Mahan K, Frierdich G, Samson L (1987) L-homocysteic acid: an endogenous excitotoxic ligand of the NMDA receptor. Brain Res Bull 19:597-602.

Parks AL, Cook KR, Belvin M, Dompe NA, Fawcett R, Huppert K, Tan LR, Winter CG, Bogart KP, Deal JE, Deal-Herr ME, Grant D, Marcinko M, Miyazaki WY, Robertson S, Shaw KJ, Tabios M, Vysotskaia V, Zhao L, Andrade RS, et al. (2004) Systematic generation of high-resolution deletion coverage of the Drosophila melanogaster genome. Nat Genet 36:288-292.

Pawlu C, DiAntonio A, Heckmann M (2004) Postfusional control of quantal current shape. Neuron 42:607-618.

Pierce VA, Mueller LD, Gibbs AG (1999) Osmoregulation in Drosophila melanogaster selected for urea tolerance. J Exp Biol 202:2349-2358.

Porrino LJ, Daunais JB, Rogers GA, Hampson RE, Deadwyler SA (2005) Facilitation of task performance and removal of the effects of sleep depri- 
vation by an ampakine (CX717) in nonhuman primates. PLoS Biol 3:e299.

Rainesalo S, Keranen T, Palmio J, Peltola J, Oja SS, Saransaari P (2004) Plasma and cerebrospinal fluid amino acids in epileptic patients. Neurochem Res 29:319-324.

Rasse TM, Fouquet W, Schmid A, Kittel RJ, Mertel S, Sigrist CB, Schmidt M, Guzman A, Merino C, Qin G, Quentin C, Madeo FF, Heckmann M, Sigrist SJ (2005) Glutamate receptor dynamics organizing synapse formation in vivo. Nat Neurosci 8:898-905.

Riikonen R (2003) Neurotrophic factors in the pathogenesis of Rett syndrome. J Child Neurol 18:693-697.

Roberts DB, ed (1998) Drosophila: a practical approach, Ed 2. Oxford: Oxford UP.

Roseman RR, Johnson EA, Rodesch CK, Bjerke M, Nagoshi RN, Geyer PK (1995) A P element containing suppressor of hairy-wing binding regions has novel properties for mutagenesis in Drosophila melanogaster. Genetics 141:1061-1074

Rothstein JD, Tsai G, Kuncl RW, Clawson L, Cornblath DR, Drachman DB, Pestronk A, Stauch BL, Coyle JT (1990) Abnormal excitatory amino acid metabolism in amyotrophic lateral sclerosis. Ann Neurol 28:18-25.

Rothstein JD, Martin LJ, Kuncl RW (1992) Decreased glutamate transport by the brain and spinal cord in amyotrophic lateral sclerosis. N Engl J Med 326:1464-1468

Ruff RL, Simoncini L, Stuhmer W (1988) Slow sodium channel inactivation in mammalian muscle: a possible role in regulating excitability. Muscle Nerve 11:502-510.

Sato H, Tamba M, Ishii T, Bannai S (1999) Cloning and expression of a plasma membrane cystine/glutamate exchange transporter composed of two distinct proteins. J Biol Chem 274:11455-11458.

Sato H, Tamba M, Kuriyama-Matsumura K, Okuno S, Bannai S (2000) Molecular cloning and expression of human xCT, the light chain of amino acid transport system xc-. Antioxid Redox Signal 2:665-671.

Sato H, Tamba M, Okuno S, Sato K, Keino-Masu K, Masu M, Bannai S (2002) Distribution of cystine/glutamate exchange transporter, system $\mathrm{x}_{\mathrm{c}}^{-}$, in the mouse brain. J Neurosci 22:8028-8033.

Schuster CM, Davis GW, Fetter RD, Goodman CS (1996) Genetic dissection of structural and functional components of synaptic plasticity. I. Fasciclin II controls synaptic stabilization and growth. Neuron 17:641-654.
Shih AY, Erb H, Sun X, Toda S, Kalivas PW, Murphy TH (2006) Cystine/ glutamate exchange modulates glutathione supply for neuroprotection from oxidative stress and cell proliferation. J Neurosci 26:10514-10523.

Spreux-Varoquaux O, Bensimon G, Lacomblez L, Salachas F, Pradat PF, Le Forestier N, Marouan A, Dib M, Meininger V (2002) Glutamate levels in cerebrospinal fluid in amyotrophic lateral sclerosis: a reappraisal using a new HPLC method with coulometric detection in a large cohort of patients. J Neurol Sci 193:73-78.

Swanson CJ, Bures M, Johnson MP, Linden AM, Monn JA, Schoepp DD (2005) Metabotropic glutamate receptors as novel targets for anxiety and stress disorders. Nat Rev Drug Discov 4:131-144.

Tomancak P, Beaton A, Weiszmann R, Kwan E, Shu S, Lewis SE, Richards S, Ashburner M, Hartenstein V, Celniker SE, Rubin GM (2002) Systematic determination of patterns of gene expression during Drosophila embryogenesis. Genome Biol 3:RESEARCH0088.

Torrents D, Mykkanen J, Pineda M, Feliubadalo L, Estevez R, de Cid R, Sanjurjo P, Zorzano A, Nunes V, Huoponen K, Reinikainen A, Simell O, Savontaus ML, Aula P, Palacin M (1999) Identification of SLC7A7, encoding $y+$ LAT-1, as the lysinuric protein intolerance gene. Nat Genet 21:293-296.

Tucci S, Pinto C, Goyo J, Rada P, Hernandez L (1998) Measurement of glutamine and glutamate by capillary electrophoresis and laser induced fluorescence detection in cerebrospinal fluid of meningitis sick children. Clin Biochem 31:143-150.

Verrey F, Closs EI, Wagner CA, Palacin M, Endou H, Kanai Y (2004) CATs and HATs: the SLC7 family of amino acid transporters. Pflügers Arch 447:532-542.

Wagner CA, Lang F, Broer S (2001) Function and structure of heterodimeric amino acid transporters. Am J Physiol Cell Physiol 281:C1077-C1093.

Xiong WC, Okano H, Patel NH, Blendy JA, Montell C (1994) repo encodes a glial-specific homeo domain protein required in the Drosophila nervous system. Genes Dev 8:981-994.

Yager J, Richards S, Hekmat-Scafe DS, Hurd DD, Sundaresan V, Caprette DR, Saxton WM, Carlson JR, Stern M (2001) Control of Drosophila perineurial glial growth by interacting neurotransmitter-mediated signaling pathways. Proc Natl Acad Sci USA 98:10445-10450. 